\title{
Complete genetic characterization of a Brazilian dengue virus type 3 strain isolated from a fatal outcome
}

\section{Marize Pereira Miagostovich/ ${ }^{+}$, Flávia Barreto dos Santos, Túlio Machado Fumian, Flávia Ramos Guimarães, Eliane Veiga da Costa, Fernando Neto Tavares, Janice O liveira Coelho*, Rita Maria Ribeiro Nogueira}

Departamento de Virologia, Instituto Oswaldo Cruz-Fiocruz, Av. Brasil 4365, 21040-900 Rio de Janeiro, RJ, Brasil *Instituto de Pesquisa Clínica Evandro Chagas-Fiocruz, RJ, Brasil

We have determined the complete nucleotide and the deduced amino acid sequences of Brazilian dengue virus type 3 (DENV-3) from a dengue case with fatal outcome, which occurred during an epidemic in the state of Rio de Janeiro, Brazil, in 2002. This constitutes the first complete genetic characterization of a Brazilian DENV-3 strain since its introduction into the country in 2001. DENV-3 was responsible for the most severe dengue epidemic in the state, based on the highest number of reported cases and on the severity of clinical manifestations and deaths reported.

Key words: dengue virus type 3 - complete genome - Brazil

Dengue viruses (DENV) 1 to 4 are members of the genus Flavivirus of the family Flaviviridae and are responsible for the most important human viral disease transmitted by arthropod vectors in terms of morbidity and mortality and, as such, are a major emerging problem in tropical and subtropical areas in the world (Rosen 1999).

The genomic RNA of $\sim 11 \mathrm{~kb}$ in length is a single strand of positive polarity constituted by a single open reading frame (ORF) flanked by an untranslated region (UTR) in the 5'and 3' termini. The ORF codes for three structural proteins: capsid (C), membrane (prM/M), and envelope (E) and for seven non structural proteins (NS1, NS2A, NS2B, NS3, NS4A, NS4B, and NS5), resulting from the cleavage of a single polyprotein of 3386-3433 amino acids (Chambers et al. 1990, Lindenbach \& Rice et al. 2001).

On the American continent, the increase in DENV activities resulted in the reported laboratory-confirmed cases of dengue fever (DF) and dengue hemorrhagic fever/dengue shock syndrome (DHF/DSS) in 24 countries, with a wide case fatality rate ranging from 1 to $11.9 \%$ from one country to another (Pinheiro \& Chuit 1998).

During the 1990s, the epidemiology of DF/DHF was aggravated by the reintroduction of DENV-3 on the American continent, first reported in 1994 in Nicaragua and Panama (Anonymous 1995). The low herd immunity to DENV-3, given by the absence of that serotype for more than 20 years in some countries, allowed the rapid spread of that serotype to the Caribbean Islands and South America in the years that followed (Pinheiro \& Corber 1997, Rigau-Perez et al. 1998, da Silva Junior et al. 2002). In

Financial support: Papes III-Fiocruz (0250250205), Faperj (E-6/152.490/2002), CNPq (501564/03-9)

${ }^{+}$Corresponding author: marizepm@ioc.fiocruz.br

Received 9 January 2006

Accepted 27 March 2006
Latin America, over 1,000,000 DF cases and more than 17,000 DHF cases including 225 fatalities were reported during 2002 alone (Guzman \& Kouri 2003).

The phylogenetic analysis based on the sequences of the prM/M- E gene regions revealed four genotypes for DENV-3 (I- H-87 prototype, Philippines, Malaysia, Indonesia and Fiji, II- Singapore and Thailand strains, III- Sri Lanka and Indian and IV- Puerto Rico) and showed that genotype III has been circulating on the American Continent and, consequently, has led to the introduction of this genotype in Brazil (Lanciotti et al. 1994, Anonymus 1995, Miagostovich et al. 2002).

In Brazil, the first cases of DENV-3 disease were reported in the summer of 2000/2001 in the state of Rio de Janeiro (Nogueira et al. 2001). After the DENV-3 introduction a period of co-circulation of DENV-1, 2, and 3, was initially observed, followed by a severe epidemic caused by the newly introduced serotype (Nogueira et al. 2002, De Simone et al. 2004).

Given that virus' genetic diversity may influence disease severity, this particular genotype has been previously recognized as producing more DHF in Sri Lanka (Lanciotti et al. 1994), we performed the first complete genome characterization of a Brazilian DENV-3 strain isolated from a DSS fatal case.

\section{MATERIALS AND METHODS}

Virus strains - The DENV-3 strains analyzed in this study were obtained from the collection of the Flavivirus Laboratory, Department of Virology, Instituto Oswaldo Cruz- Fiocruz. The strains were isolated by inoculation into Aedes albopictus C6/36 cell lines (Igarashi 1978) and the serotype was identified by immunofluorescence using type-specific monoclonal antibodies (Gubler et al. 1984). The first passages were used for RNA extraction, amplification, and direct sequencing of the products. The Brazilian DENV-3 strains (BR71125/01; BR/74886/02; BR77475/03) and the others used for comparative analysis in this study are listed in Table I. 
TABLE I

Dengue virus type 3 strains used in this study

\begin{tabular}{|c|c|c|c|c|c|c|}
\hline $\begin{array}{l}\text { Strain } \\
\text { identification no. }\end{array}$ & $\begin{array}{l}\text { Strain } \\
\text { origin }\end{array}$ & $\begin{array}{l}\text { Disease } \\
\text { severity }\end{array}$ & $\begin{array}{l}\text { Isolation } \\
\text { year }\end{array}$ & $\begin{array}{l}\text { GenBank } \\
\text { accession no. }\end{array}$ & $\begin{array}{l}\text { Region } \\
\text { analyzed }\end{array}$ & References \\
\hline $\mathrm{BR} / 74886 / 02$ & Brazil & DSS & 2002 & AY679147 & Complete genome & This study \\
\hline $\mathrm{BR} / 68784 / 00$ & Brazil & DF & 2000 & AY038605 & $\mathrm{E}$ & Miagostovich et al. 2001 \\
\hline BR71125/01 & Brazil & DF & 2001 & Not available & 3' end, 10,268 - 10,707 & This study \\
\hline BR77475/03 & Brazil & DF & 2003 & Not available & 3' end, 10,268 - 10,707 & This study \\
\hline MART/1243/99 & Martinique & $a$ & 1999 & AY099337 & Complete genome & Peyrefitte et al. 2003 \\
\hline SRILAN/1266/00 & Sri Lanka & $a$ & 2000 & AY099336 & Complete genome & Peyrefitte et al. 2003 \\
\hline China80-2 & China & $a$ & 1980 & AF317645 & Complete genome & Unpublished \\
\hline $\mathrm{H}-87$ & Philipines & $a$ & 1956 & M93130 & Complete genome & Osatomi \& Sumiyoshi 1990 \\
\hline SLEMAN/78 & Indonesia & $a$ & 1978 & AY648961 & Complete genome & Blaney et al. 2004 \\
\hline $8120 / 95$ & Singapore & $a$ & 1995 & AY766104 & Complete genome & Unpublished \\
\hline 98902890 & Indonesia & $\mathrm{DF}$ & 1998 & AB189128 & Complete genome & Unpublished \\
\hline 98901517 & Indonesia & DHF & 1998 & AB189127 & Complete genome & Unpublished \\
\hline 98901437 & Indonesia & DSS & 1998 & AB189126 & Complete genome & Unpublished \\
\hline 98901403 & Indonesia & DSS & 1998 & AB189125 & Complete genome & Unpublished \\
\hline LN8180 & Malaysia & DF & 1994 & AY338492 & $\mathrm{E}$ & Fong et al. 2004 \\
\hline LN7029 & Malaysia & DHF & 1994 & AY338493 & $\mathrm{E}$ & Fong et al. 2004 \\
\hline LN7933 & Malaysia & DSS & 1994 & AY338494 & $\mathrm{E}$ & Fong et al. 2004 \\
\hline LN5547 & Malaysia & ENC & 1992 & AF147457 & $\mathrm{E}$ & Fong et al. 2004 \\
\hline LN6083 & Malaysia & ENC & 1994 & AF147460 & $\mathrm{E}$ & Fong et al. 2004 \\
\hline Den-1/ BR/01MR & Brazil & $a$ & 2001 & AF513110 $b$ & Complete genome & Duarte dos Santos et al. 2002 \\
\hline Den-2/BR64022/98 & BrazilL & $a$ & 1998 & AF489932 $b$ & Complete genome & Santos et al. 2002 \\
\hline Den-4/814669/83 & Dominica & $a$ & 1981 & AF326573 $b$ & Complete genome & Durbin et al. 2001 \\
\hline
\end{tabular}

$\bar{a}$ : not informed ; $b$ : strains used as outgroups; DSS: dengue shock symdrome; DF: dengue fever; DHF: dengue hemorrhagic fever; ENC: encephalitogenic.

Serological methods - IgM capture enzyme-linked immunosorbent assay (MAC-ELISA) and G- ELISA were performed in order to detect specific IgM and IgG dengue antibodies by using serotype-specific antigens mixture (DENV-1, DENV-2, and DENV-3) as described previously by Kuno et al. (1987) and Miagostovich et al. (1999). The IgG-ELISA was performed for the characterization of dengue immune response as primary or secondary infection.

RNA extraction - Viral RNA was extracted from clinical samples (sera and fresh tissue) using QIAamp Viral Mini Kits (Qiagen, Inc., Valencia, CA) according to the manufacturer's protocol.

Immunohistochemical procedure - Sections of formalin-fixed, paraffin-embedded tissues were processed using the streptavidin-biotin method according to the manufacturer's protocol (Kit LSAB, DAKO, US). Monoclonal antibodies for DENV-1, 2, and 3 were kindly provided by Dr D Gubler (Centers for Disease Control and Prevention, Colorado, US).

Reverse transcription-polymerse chain reaction ( $R T$ $P C R$ ). RT-PCR for detecting and typing DENV in acute sera and fresh tissues available was carried out according to Lanciotti et al. (1992).

Primer design for sequencing - Synthetic oligonucleotide primer pairs were designed to amplify overlapping fragments of approximately $500 \mathrm{bp}$ spanning the complete DENV-3 genome based on the full-length sequence of a representative DENV-3. The sequence of the strain 80-2 (accession number AF317645) was retrieved from the National Center for Biomedical Investigation database (NCBI, http://www.ncbi.nlm.nih.gov) and the primers were designed manually. To assure the sequencing of the fragments, internal primers were also designed. The sequences of the oligonucleotide primers used for the RTPCR are available upon request.

RT-PCR amplification - Viral RNAs were extracted from the culture supernatant of infected cells and fragments were amplified using an one-tube procedure. Briefly, the RT-PCR mixture consisted of $12.5 \mu$ l of $2 \times$ PCR Master Mix (Promega, US), $1.5 \mu \mathrm{l}$ of $100 \mathrm{mM}$ dithiotreitol, each primer at a final concentration of $10 \mu \mathrm{M}$ and $1 \mu \mathrm{l}$ of $5 \mathrm{U}$ of AMV-RT (Invitrogen, US). Five microliters of the extracted RNA were reverse transcribed at $42^{\circ} \mathrm{C}$ for $60 \mathrm{~min}$, followed directly by 40 cycles of amplification consisting of $94^{\circ} \mathrm{C}$ for $30 \mathrm{~s}, 57-60^{\circ} \mathrm{C}$, depending on the primers used, for 1 min, and $72^{\circ} \mathrm{C}$ for $2 \mathrm{~min}$, with a final extension at $72^{\circ} \mathrm{C}$ for 10 min. Amplification was conducted using a Model 9700 thermal cycler (Perkin-Elmer, US) or PTC-200-60 thermo cycler (MJ Research, US).

Sequencing of PCR products - The cDNA fragments amplified by PCR were directly sequenced in both directions using a BigDye Terminator Cycle Sequencing Ready Reaction kit (Applied Biosystems, US), 3.2 pmol of primers combined with $200 \mathrm{ng}$ of DNA, after purification using PCR purification kit or gel extraction kit (Qiagen, US). Thermocycling conditions consisting of 25 cycles of $96^{\circ} \mathrm{C}$ for $30 \mathrm{~s}, 50^{\circ} \mathrm{C}$ for $1 \mathrm{~min}$ and $60^{\circ} \mathrm{C}$ for $4 \mathrm{~min}$ were used as recommended by the manufacturer. After purification us- 
ing Centri-Sep columns (Princeton Separations, US) the DNA was dried at $37^{\circ} \mathrm{C}$, overnight. The pellet was resuspended in $20 \mu \mathrm{l}$ of template suppression reagent, heated for $2 \mathrm{~min}$ at $95^{\circ} \mathrm{C}$ and kept on ice until $10 \mu \mathrm{l}$ was loaded on an Applied Biosystems Prism 310 Sequencer using performance-optimized polymer 6 (Applied Biosystems).

Sequence and phylogenetic analysis - The analysis of the nucleotide sequences fragments was performed using Chromas software version 1.45 (http://www. technelysium.com.au/chromas $14 x . h$ tml), the nucleotide and amino acid identities were determined using BLAST (http://www.ncbi.nlm.nih.gov.Entrez) and DNAsis version 2.6 (Hitachi, US). A phylogenetic tree was constructed using MEGA 2 software (Sudhir et al. 2001), using the Neighbor Joining, Tamura Nei method. Representative sequences from DENV-1, 2, and 4 were used as out groups to root the tree. A bootstrap of 500 replications, was used to estimate the reliability of the predicted tree.

\section{RESULTS}

We determined a 10,707 nucleotides (nts) sequence for DENV-3 strain BR/74886/02 (GenBank access number AY 679147) isolated from a liver of DSS fatal dengue case occurring during the peak of the DENV-3 epidemic, in the summer of 2002 in Rio de Janeiro. DENV-3 (BR74886/02) was isolated from the liver and from the serum of a 21year-old woman presenting fever, severe headache, myalgia, arthralgia, vomiting, prostration, and exhanthem, which evolved into a hypovolemic shock (Table II). The infecting serotype was also identified by RT-PCR (Fig. 1) in the spleen, lung, and brain, and was detected in formalized liver, spleen, and brain using immunohistochemistry dengue antigen. Titer $<1 / 40$ for specific IgG confirmed a primary dengue infection (Table II).

The genetic comparison and phylogenetic analysis based on the full length DENV-3 sequences from strains available in the GenBank database clustered together the Brazilian and Martinique strains, reflecting a high level of identity between these strains (Fig. 2, Table III) and characterized the Brazilian DENV-3 as belonging to genotype III. An 11-nucleotide-long insertion between positions 10,275 and 10,276 in the 3 UTR (AGTGAAAAAGA) was observed. The nucleotide sequences corresponding to the 3 UTR (position 10,268 to 10,707) from the strains BR71125/01 and BR77475/03 isolated from DF cases occurring before and after the epidemic period were also

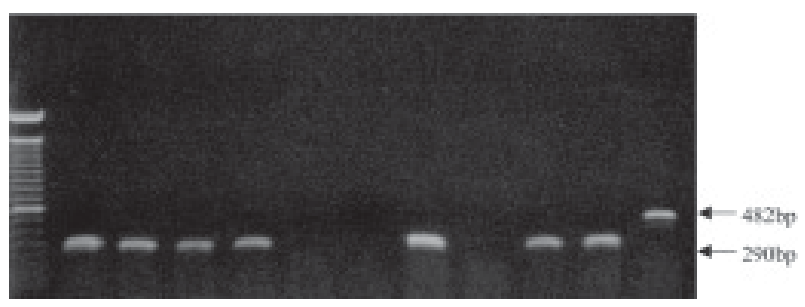

Fig. 1: characterization of dengue virus type 3 (DENV-3) by reverse transcription-polymerase chain reaction (RT-PCR). Ethidium bromide $1 \%$ stained agarose gel showing RT-PCR nested products. Lanes1: 100-bp ladder (Gibco); 2, 3, 4, and 5: samples of liver, spleen, lung, and brain from the same DSS fatal case; 6 and 7: negative samples; 8: posite DENV-3 sample; lane 9: water; 10 and 11: DENV-3 controls; 12: DENV-1 control.

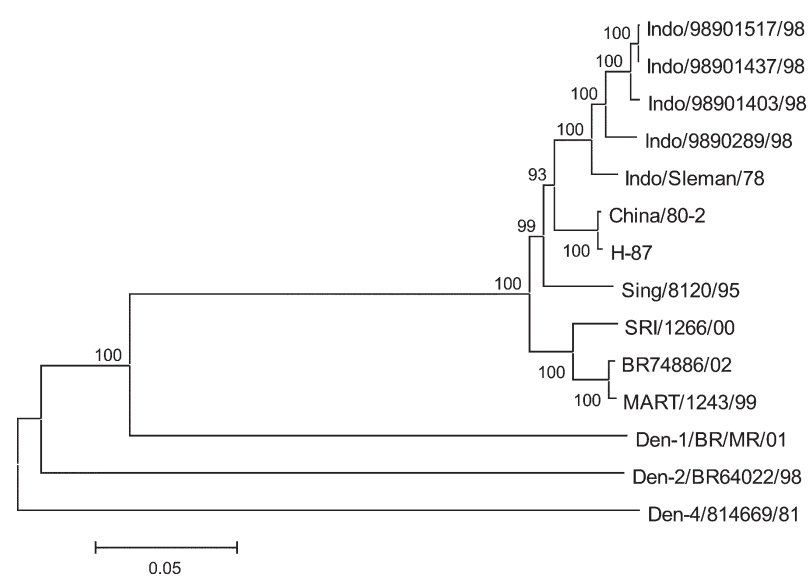

Fig. 2: phylogenetic analysis of full-length dengue virus type 3 (DENV-3) genomes. The complete nucleotide sequences of four representative DENV-3 strains were analyzed using the Neighbor Joining, Tamura Nei, bootstrap 500 replications. Representative strains of DENV-1, DEN-2, and DEN-4 were used to root the tree. Each strain is abbreviated with the country of origin, followed by the year of isolation and the strain designation. Bootstrap values are indicated in bold at the branch points.

determined and show the same insertion in that region. The comparison of the of BR74886/02 deduced amino acid sequence to other DENV-3 representative strains from genotype III (Mart/1234/99; SriL/1266/00) showed no amino acid changes in the region coding for structural and nonstructural proteins with the exception of NS4A,

TABLE II

Virological and serological results of clinical specimens from a single dengue shock syndrome patient with fatal outcome by using different methodologies

\begin{tabular}{llllll}
\hline & \multicolumn{3}{c}{ Methods } \\
\cline { 2 - 6 } Clinical specimens & Virus isolation & RT-PCR & Immunohistochemistry & Mac-ELISA & G-ELISA \\
\hline Serum & DENV-3 & DENV-3 & - & $<1 / 10$ & $<1 / 40$ \\
Liver & DENV-3 & DENV-3 & Positive & - & - \\
Spleen & Negative & DENV-3 & Positive & - & - \\
Lung & Negative & DENV-3 & Negative & - & - \\
Brain & Negative & DENV-3 & Positive & - & - \\
\hline
\end{tabular}

RT-PCR: reverse-transcription-polymerase chain reaction 


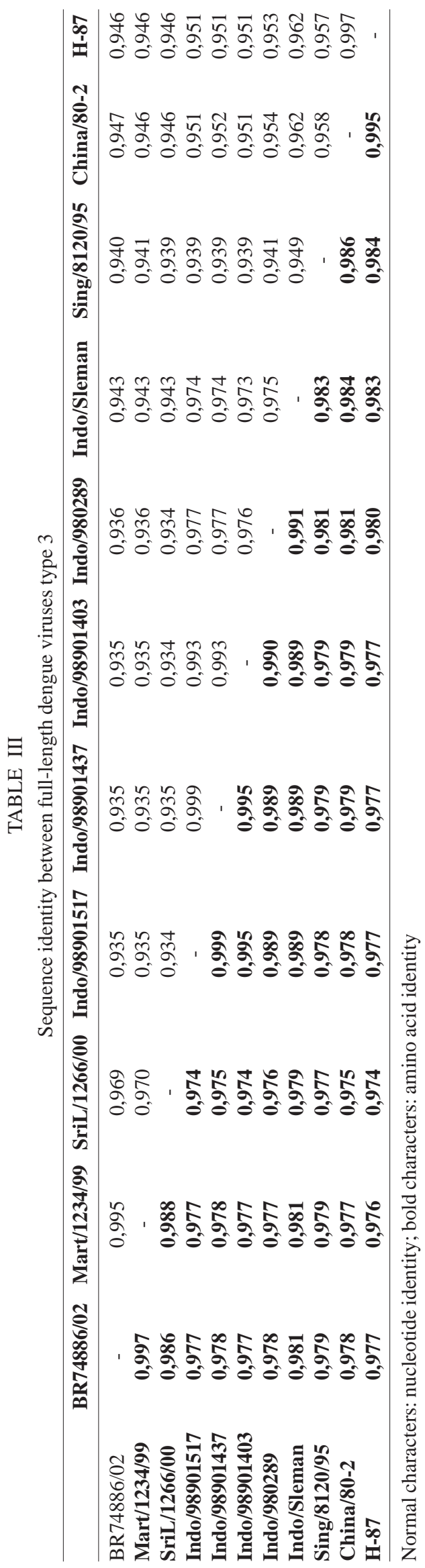

where one non conservative substitution - arginine to lysine $-(\mathrm{R} \rightarrow \mathrm{K})$ in position 20 was noted for the Brazilian strain BR/74886/02 (data not shown).

In order to investigate whether any change in the $\mathrm{E}$ gene could be correlated to a more severe case leading to a fatal outcome, the amino acid sequence from the E protein of the Brazilian DENV-3 (DSS) was compared to those of strains with a wide range of disease severity (DF, DHF, DSS, and encephalitis) (Table IV). The deduced amino acid sequence similarity among isolates ranged from $97.3 \%$ (DHF and DSS strains from Indonesia/1998) to $98.9 \%$ (DF Brazilian strain/2000). The sequence analysis showed only one amino acid difference specific to the Brazilian DSS strain where one substitution - lysine to arginine $-(K \rightarrow R)$ in position 391 of the $\mathrm{E}$ protein was noted for the Brazilian strain BR/74886/02.

\section{DISCUSSION}

In 2002, DENV-3 was responsible for the most severe epidemic occurring in the state of Rio de Janeiro, an epidemic which occurred after 16 years of DENV activity in the country (Nogueira et al. 2005). During this period it was demonstrated that individuals infected by DENV- 3 presented signs indicating a more severe disease (Passos et al. 2004).

The severity of the disease and the occurrence of deaths resulting from primary infections during the epidemic were partially explained by the virulence of this particular genotype (genotype III/Indian subcontinent), confirming that some DENV strains can be more virulent than others, that these represent an important risk factor for DHF/DSS and that antibody-dependent enhancement (ADE) itself does not explain all cases of severe disease (Rosen 1996, Halstead 1980, Messer et al. 2002, Nogueira et al. 2005). According to Lanciotti et al. (1994) a genetic shift in this genotype was responsible for the emergence of DHF in Sri Lanka, since no increase in virus transmission or shift in serotype occurred in Sri Lanka during this period.

For this reason we chose to sequence the complete genome of a Brazilian DENV-3 strain causing DSS, which led to a fatal outcome in a primary infection case where no individual risk factors were reported suggesting that the virulence of the strain might be responsible for the outcome. Chronic diseases such as bronchial asthma, diabetes mellitus, and sickle cell anaemia are considered risk factors for development of DHF/DSS (Bravo et al. 1987).

Recently, a global study using phylogenetic analysis of DENV-3 isolated from Sri Lanka up to 10 years after the emergence of DHF and from East African and Latin American, suggested that this genotype was introduced from the Indian subcontinent into East Africa in the 1980s and from Africa into Latin America in 1994 (Messer et al. 2003). Other studies using DENV-3 strains from the Latin American Region also suggested a single introduction of DENV3 on the continent and a subsequent diversification of the virus population (Usuku et al. 2001, Messer et al. 2002, 2003, Uzcategui et al. 2003).

The comparative analysis of the alignment of the deduced amino acid sequences of the E protein from DENV3 (Table IV) suggested there is no correlation between 


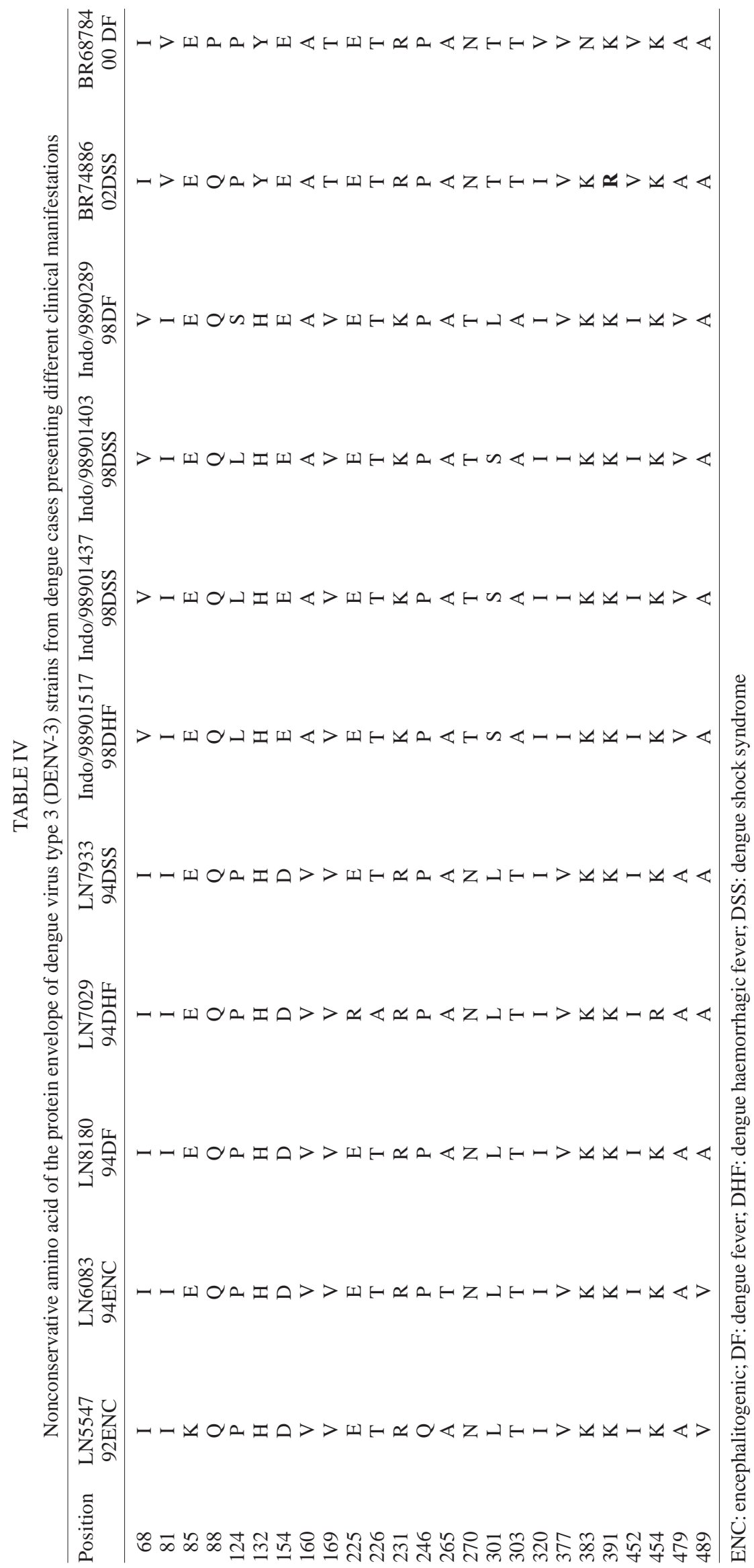


changes in the $\mathrm{E}$ protein according to clinical manifestations. This, in spite of the fact that DENV-3 was responsible for the most severe dengue epidemic in the state, not only judging by the highest number of reported cases but also by the severity of clinical manifestations presented by the patients and by the number of deaths reported (Nogueira et al. 2005). Previously, Fong et al. (2004) suggested that neurovirulence of four encephalitogenic strains isolated in Malaysia (1992-1994) cannot be attributed to this protein.

Although our understanding of virus-specified determinants of virulence has been acquired indirectly, through an association between evolutionary grouping of virus strains and their epidemiological and/or clinical disease presentation (Rico-Hesse 2003), several studies focusing on the molecular basis of dengue pathogenesis have attributed virulence determinants to mutations in both structural and nonstructural proteins, as well as to UTR regions of the flavivirus genome (McMinn 1997, Leitmeyer et al. 1999, Holden \& Harris 2004, Halstead et al. 2005).

The full length analysis of nucleotide and amino acid sequences of the Brazilian strain confirmed the circulation of genotype III in the state and revealed the presence of an insertion in the 3' UTR of the genome, as previously described by Peyrefitte et al. (2003) in strains from Martinique. Since the recent complete characterization of DENV-3 strains isolated in Singapore 1995 (AY766104) and Indonesia 1998 (AB189125-28) also revealed this insertion, further sequencing of other selected strains would be desirable in order to understanding when it might have been acquired.

A previous study of the genetic variation in the 3 UTR of DENV did not correlate the heterogeneity of this region with DENV pathogenesis (Shurtleff et al. 2001). However, Holden and Harris (2004) has demonstrated that 3' UTR may mediate an enhancement of DENV translation. Therefore we suggest that additional studies would be desirable to understand the evolutionary processes that generate the genetic variation represented by the insertion of $11 \mathrm{nts}$ observed and its consequence in viral RNA translation.

\section{REFERENCES}

Anonymous 1995. Dengue 3 in Central America. Dengue Surveillance, Dengue Branch, San Juan, Puerto Rico, 70 pp.

Blaney JE, Hanson CT, Firestone CY, Hanley KA, Murphy BR, Whitehead SS 2004. Genetically modified, live attenuated dengue virus type 3 vaccine candidates. Am J Trop Med Hyg 71: 811-821.

Bravo JR, Guzman MG, Kouri GP 1987. Why dengue haemorrhagic fever in Cuba? 1. Individual risk factors for dengue haemorrhagic fever/dengue shock syndrome (DHF/ DSS). Trans $R$ Soc Trop Med Hyg 81: 816-820.

Chambers TJ, Hahn CS, Galler R, Rice CM 1990. Flavivirus genome organization, expression, and replication. Annu Rev Microbiol 44: 649-688.

Da Silva Júnior JB, Siqueira Júnior JB, Coelho GE, Vilarinhos PTR, Pimenta Júnior FG 2002. Dengue in Brazil: current situation and prevention and control activities. Epidem Bull 23: 1-7.
De Simone TS, Nogueira RMR, Araújo ESM, Guimarães FR, Santos FB, Schatzmayr HG, Souza RV, Teixeira Filho G, Miagostovich MP 2004. Dengue virus (DENV) surveillance: the co-circulation of DENV-1, 2 and 3 in the state of Rio de Janeiro, Brazil. Trans R Soc Trop Med Hyg 98: 553562.

Duarte dos Santos CN, Rocha CFS, Cordeiro M, Fragoso SP, Rey F, Deubel V, Desprès P 2002. Genome analysis of dengue type-1 virus isolates between 1990 and 2001 in Brazil reveals a remarkable conservation of the structural proteins but amino acid differences in the nonstructural proteins. Virus Res 90: 197-205.

Durbin AP, Karron RA, Sun W, Vaughn DW, Reynolds MJ, Perreault JR, Thumar B, Men R, Lai CJ, Elkins WR, Chanock RM, Murphy BR, Whitehead SS 2001. Attenuation and immunogenicity in humans of a live dengue virus type- 4 vaccine candidate with a 30 nucleotide deletion in its 3'-untranslated region. Am J Trop Med Hyg 65: 405-413.

Fong M-Y, Yusup R, Yusof R, Lam S-K 2004. Neurovirulence of four encephalitogenic dengue 3 virus strains isolated in Malaysia (1992-1994) is not attributed to their envelope protein. Trans R Soc Trop Med Hyg 98: 379-381.

Gubler DJ, Kuno G, Sather GE, Velez M, Oliver A 1984. Use of mosquito cell cultures and specific monoclonal antibodies in surveillance for dengue viruses. Am J Trop Med Hyg 33: 158-165.

Guzman MG, Kouri G 2003. Dengue and dengue hemorrhagic fever in the Americas: lessons and challenges. J Clin Virol 27: 1-13.

Halstead SB 1980. Dengue haemorrhagic fever, a public health problem and a field for researches. Bull WHO 58: 1-21.

Halstead SB, Heinz FX, Barrett ADT, Roehrig JT 2005. Dengue virus: molecular basis of cell entry and pathogenesis. Vaccine 23: 849-856.

Holden KL, Harris E 2004. Enhancement of dengue virus translation: role of the 3 untranslated region and the terminal 3 stem-loop domain. Virology 329: 119-133.

Igarashi A 1978. Isolation of a Singh's Aedes albopictus cell clone sensitive to dengue and chikungunya viruses. J Gen Virol 40: 531-544.

Kuno G, Gomez I, Gubler DJ 1987. Detecting artificial antidengue IgM immune complexes using an enzyme-linked immunosorbent assay. Am J Trop Med Hyg 36: 153-159.

Lanciotti RS, Calisher CH, Gubler DJ, Vorndam V 1992. Rapid detection and typing of dengue viruses from clinical samples by using reverse transcriptase-polymerase chain reaction. J Clin Microbiol 30: 545-551.

Lanciotti RS, Lewis JG, Gubler DJ, Trent DW 1994. Molecular evolution and epidemiology of dengue-3 viruses. J Gen Virol 75: 65-75.

Leitmeyer KC, Vaughn DW, Watts DM, Salas R, Villalobos de Chacon I, Ramos C, Rico-Hesse R 1999. Dengue virus structural differences that correlate with pathogenesis. $J$ Virol 73: 4738-4747.

Lindebach BD, Rice CM 2001. Flaviviridae: The viruses and their replication. In DM Knipe, PM Howley (eds), Fields Virology, 4th ed., Lippincott Williams and Wilkins, Philadelphia, p. 991-1041. 
McMin PC 1997. The molecular basis of virulence of the encephalitogenic flavivivruses. J Gen Virol 78: 2711-2722.

Messer WB, Gubler DJ, Harris E, Sivananthan K, De Silva AM 2003. Emergence and global spread of a dengue serotype 3, subtype III virus. Emerg Infect Dis 9: 800-808.

Messer WB, Vitarana UT, Sivananthan K, Elvtigala J, Preethimala LD, Ramesh R, Withana N, Gubler DJ, De Silva AM 2002. Epidemiology of dengue in Sri Lanka before and after the emergence of epidemic dengue hemorrhagic fever. Am J Trop Med Hyg 66: 765-773.

Miagostovich MP, Santos FB, De Simone TS, Costa EV, Filippis AMB, Schatzmayr HG 2002. Genetic characterization of dengue virus type 3 isolates in the State of Rio de Janeiro, 2001. Brazilian J Med Biol Res 35: 1-4.

Miagostovich MP, Vorndam V, Araújo ESM, Santos FB, Schatzmayr HG, Nogueira RMR 1999. Evaluation of IgG enzyme-linked immunosorbent assay for dengue diagnosis. J Clin Virol 14: 183-189.

Nogueira RMR, Miagostovich MP, Schatzmayr HG 2002. Dengue virus in Brazil. Dengue Bull 26: 77-83.

Nogueira RMR, Miagostovich MP, Filippis AMB, Pereira MAS, Schatzmayr HG 2001. Dengue virus type 3 in Rio de Janeiro, Brazil. Mem Inst Oswaldo Cruz, 96: 925-926.

Nogueira RMR, Schatzmayr HG, Filippis AMB, Cunha RV, Souza LJ, Guimarães FR, Araújo ESM, De Simone TS, Baran M, Teixeira Junior G, Miagostovich MP 2005. Dengue virus type 3, Brazil 2002. Emegr Infect Dis 11: 13761381.

Osatomi K, Sumiyoshi H 1990. Complete nucleotide sequence of dengue type 3 virus genome RNA. J Virol 176: 643-647.

Passos MNP, Santos LMJ, Pereira MRR, Casali CG, Fortes BPMD, Valencia LIO, Alexandre AJ, Medronho RA 2004. Clinical differences observed in patients with dengue caused by different serotypes in the epidemic of 2001/2002 occurred in Rio de Janeiro. Rev Soc Bras Med Trop 37: 293295.

Peyrefitte CN, Couissinier-Paris P, Mercier-Perennee V, Bessaud M, Martial J, Kenane N, Durand J-P A, Tolou HJ 2003.
Genetic characterization of newly reintroduced dengue virus type 3 in Martinique (French West Indies). J Clin Microbiol 41: 5195-5198.

Pinheiro FP, Chuit R 1998. Emergence of dengue hemorrhagic fever in the Americas. Infect Med 15: 244-251.

Pinheiro FP, Corber SJ 1997. Global situation of dengue and dengue hemorrhagic fever and its emergence in the Americas. WHO Stat quartely 50: 161-169.

Rigau-Perez JG, Clark GG, Gubler DJ, Reiter P, Sanders EJ, Vorndam AV 1998. Dengue and dengue haemorrhagic fever. Lancet 352: 971-977.

Rico-Hesse R 2003. Microevolution and virulence of dengue viruses. Virus Res 59: 315-341.

Rosen L 1996. Dengue hemorrhagic fever. Bul Soc Pat Exotique 89: 91-94.

Rosen L 1999. Comments on the epidemiology, pathogenesis and control of dengue. Med Trop 59: 495-498.

Santos FB, Miagostovich MP, Nogueira RMR, Edgil D, Schatzmayr HG, Riley LW, Harris E 2002. Complete nucleotide sequence analysis of a Brazilian dengue virus type 2 strain. Mem Inst Oswaldo Cruz, 97: 991-995.

Sudhir Kumar, Koichiro Tamura, Ingrid B. Jakobsen, Masatoshi Nei 2001. MEGA2: Molecular Evolutionary Genetics Analysis software, Arizona State University, Tempe, Arizona, US.

Shurtleff AC, Beasley DWC, Chen JJY, Ni H, Suderman MT, Wang H, Xu R, Wang E, Weaver SC, Watts DM, Russell KL, Barrett ADT 2001. Genetic variation in the 3' noncoding region of dengue viruses. Virology 281: 75-87.

Usuku S, Castillo L, Sugimoto C, Noguchi Y, Yogo Y, Kobayashi N 2001. Phylogenetic analysis of dengue-3 viruses prevalent in Guatemala during 1996-1998. Arch Virol 146: 13811390.

Uzcategui NY, Comach G, Camacho D, Salcedo M, Cabello de Quintana M, Jiménez M, Siera G, Cuello de Uzcategui R, James WS, Turner S, Holmes EC, Gould EA 2003. Molecular epidemiology of dengue virus type 3 in Venezuela. $J$ Gen Virol 84: 1569-1575. 